\title{
Mastectomy Blood Loss: Can We Predict the Need for Blood Transfusion?
}

\author{
Joe Nat Clegg-Lamptey*, Jonathan C. B. Dakubo \\ Department of Surgery, School of Medicine and Dentistry, Accra, Ghana \\ Email: ${ }^{*}$ clegglamptey@chs.edu.gh
}

Received 12 September 2014; revised 11 October 2014; accepted 8 November 2014

Copyright (C) 2014 by authors and Scientific Research Publishing Inc.

This work is licensed under the Creative Commons Attribution International License (CC BY). http://creativecommons.org/licenses/by/4.0/

c) (i) Open Access

\section{Abstract}

Background: Bleeding during total mastectomy and axillary clearance is inevitable, and blood transfusion is often required when bleeding is excessive. Objectives: To predict the probability of transfusion, we tested the hypothesis: "The blood loss during total mastectomy and axillary clearance in Accra is related to the stage of the disease and the size of the breast". Design: Patients undergoing total mastectomy and axillary clearance were prospectively studied from June 2008 to June 2011. The breast and used swabs were weighed immediately after surgery, and patients' full blood count was checked before and after surgery. Setting: Surgical wards and theatres of the Korle Bu Teaching Hospital, Accra. Results: There were 80 women, aged 31 to 85 (Mean 50, SD 3.4) years, with body mass index between 20 and 46 (mean 23.7, median 28 ). Fifty one (63.8\%) had Stage 3 disease, and 47 (58.8\%) required neoadjuvant chemotherapy. Pre-operative haemoglobin was $9.5 \mathrm{~g} / \mathrm{dl}$ to $14.9 \mathrm{~g} / \mathrm{dl}$ (mean $11.6 \mathrm{~g} / \mathrm{dl}$, SD 1.1). Post-operative haemoglobin was $9.2 \mathrm{~g} / \mathrm{dl}$ - 13.4 $\mathrm{g} / \mathrm{dl}$ (mean 10.9, SD 0.97). The mean drop in haemoglobin level was $0.75 \mathrm{~g} / \mathrm{dl}$. None of the 80 patients received blood transfusion. There was a linear increase in breast weight with increasing BMI. Blood loss ranged from $95 \mathrm{~g}$ to $1185 \mathrm{~g}$, with majority $(59 ; 73.8 \%)$ losing between 100 and 400 gram blood. Only 2 patients (2.5\%) lost more than $1000 \mathrm{~g}$ of blood. Less than $400 \mathrm{~g}$ of blood was lost with breast weights below $2 \mathrm{~kg}$. Above that, blood loss increased to more significant volumes. Conclusions: Blood loss during total mastectomy and axillary clearance in Accra was directly related to the size of the breast. There was, however, inconclusive association between tumour stage and blood loss.

\section{Keywords}

Total Mastectomy and Axillary Clearance, Bleeding, Haemorrhage, Blood Transfusion

${ }^{*}$ Corresponding author. 


\section{Introduction}

Bleeding during surgery is inevitable but has dire consequences when it becomes excessive. Surgeons and anaesthetists have therefore always employed a wide variety of techniques to reduce blood loss. In spite of the everpresent danger of transmitting diseases such as Hepatitis B, Hepatitis C and HIV, blood transfusion is often employed whenever blood loss is significant.

Total mastectomy and axillary claeance is an operation that is often carried out for locoregional treatment of breast cancer and is associated with apparent significant blood loss. One of the techniques that was employed decades ago to reduce blood loss during mastectomy was hypotensive anaesthesia [1]. More recently Adrenaline infiltration [2] and flap dissection using electrocautery (diathermy) [3] [4], $\mathrm{CO}_{2}$ laser [5] and harmonic scalpel [6] [7] are some of the techniques and equipment reportedly used.

In Ghana where over $60 \%$ of breast cancers are locally advanced, most operations for the disease involve total mastectomy and axillary clearance rather than breast conservation surgery (lumpectomy) [8]. Because of tumour-induced angiogenesis these large tumours are observed to bleed excessively during surgery, especially when the breasts are large. There is thus the potential of significant blood loss in our mastectomy patients. Blood, however, is not always readily available for transfusion, because blood transfusion services in Ghana are plagued with the perennial problem of low stock levels.

Most patients for total mastectomy and axillary clearance at the Korle Bu Teaching hospital (KBTH) have blood grouped and cross matched in anticipation of possible transfusion, but in spite of the observed excessive bleeding we had observed that few patients ultimately receive blood transfusion.

It is desirable to be able to predict the probability of blood transfusion before mastectomy, so that we can improve the efficacy of the ordering system for maximum utilisation of blood [9]. We therefore sought to test a hypothesis that "the blood loss during total mastectomy and axillary clearance in Accra is related to the stage of the disease and the size of the breast”.

\section{Methods}

Consenting patients undergoing total mastectomy and axillary clearance on a surgical unit at the Korle Bu Teaching Hospital (KBTH) were prospectively studied, consecutively, from June 2008 to June 2011. This surgical unit attends to an average of 100 breast cancer patients each year. The main components of the study were determination of the stage of the disease, size of breast (weight/volume) and the amount (volume/weight) of blood lost during total mastectomy and axillary clearance. The patients were all Ghanaian women.

The inclusion criteria were patients with breast cancer who were due to have total mastectomy and axillary clearance. Exclusion criteria were patients for toilet mastectomy without axillary clearance and those with bilateral disease.

The disease was staged by the TNM and the Manchester Classifications. The patients' height and weight were determined before surgery. Neoadjuvant chemotherapy was administered to downstage locally advanced tumours. Those patients were regularly reviewed after 2 - 3 cycles and surgery performed if there was response to chemotherapy. If there was no response or the disease progressed, surgery was carried out if it was feasible otherwise the regime was changed. The operations were carried out by two surgeons using identical operating technique. Skin flaps were raised using monopolar diathermy. Axillary dissection was by level II axillary clearance, using scissors and diathermy for dissection, and diathermy and suture ligation for haemostasis. The breast was weighed immediately after removal using an electronic scale. Blood loss was determined by weighing all used swabs before and after surgery.

The patients' haemoglobin level was checked before surgery and 48 hours after surgery. Patients were to receive blood transfusion during surgery if the anaesthetist judged it was indicated by the amount of blood lost and the patient's physiological status. Post-operatively, patients were to have haemo-transfusion if their haemoglobin level dropped to $8 \mathrm{~g} / \mathrm{dl}$ or if they developed anaemic symptoms with haemoglobin levels between 8 and $10 \mathrm{~g} / \mathrm{dl}$.

Data was compiled using Microsoft Excel software. Analysis of mean, standard deviation and mode, as well as the ANOVA and Spearmen Correlation were performed with Spss version 20; the level of significance was set at 0.05 .

\section{Results}

There were 80 women, aged between 31 and 85 (Mean 50, SD 3.4) years. They were of varying parity (0 - 7) as 
detailed in Table 1. Their body surface area (BSA) calculated from the height and weight ranged from 1.53 to 2.28. Body mass index (BMI) ranged from 20 to 46 (mean 23.7, median 28). The left breast was affected in 33 patients and the right in 47.

Fifty-one (63.8\%) of the patients had Stage 3 disease at presentation. The details of stage of presentation are shown in Table 2. Forty-seven (58.8\%) had neoadjuvant chemotherapy, with number of cycles ranging from 2 to 6. The medicines received were CAF (37), AC (6), CMF (3) and Capecitabine-Paclitaxel (1). None of them had neoadjuvant tamoxifen or radiotherapy.

Response to neoadjuvant chemotherapy was as follows: complete response (3), partial response (18), stable disease (24), and disease progression (2).

Pre-operative haemoglobin ranged from $9.5 \mathrm{~g} / \mathrm{dl}$ to $14.9 \mathrm{~g} / \mathrm{dl}$ (mean $11.6 \mathrm{~g} / \mathrm{dl}$, SD 1.1). Post-operative haemoglobin, checked $48 \mathrm{~h}$ after surgery, ranged between $9.2 \mathrm{~g} / \mathrm{dl}$ and $13.4 \mathrm{~g} / \mathrm{dl}$ (mean 10.9, SD 0.97). The mean drop in haemoglobin level was $0.75 \mathrm{~g} / \mathrm{dl}$.

None of the 80 patients received blood transfusion during or after surgery.

The state of lymph nodes at surgery was as follows: no obvious enlarged nodes (4 [5\%]), mobile enlarged nodes (60 [75\%]), matted nodes (11 [13.75\%]), fixed nodes (5 [6.25\%]).

Patients with breast weight between 325 and 499 grams had a mean body mass index of 23.2. There was a linear increase in breast weight with increasing BMI (Figure 1).

\section{Blood Loss}

Table 3 shows the intra-operative blood loss, measured by weight. Losses ranged from $95 \mathrm{~g}$ to $1185 \mathrm{~g}$, with majority losing less than 300 grams (50 patients [63\%]) and Sixty three (78.8\%) lost less than 400 gram of blood. Only 2 patients (2.5\%) lost more than 1000 g of blood.

Figure 2 shows the blood loss (mean) associated with different breast sizes. This shows that there was less than $400 \mathrm{~g}$ of blood lost with breast weight below $2 \mathrm{~kg}$. Above that, blood loss increased to more significant vo-

Table 1. Parity of patients.

\begin{tabular}{cc}
\hline Parity & Number of women \\
\hline 0 & 7 \\
1 & 10 \\
2 & 18 \\
3 & 13 \\
4 & 12 \\
5 & 7 \\
6 & 8 \\
7 & 5 \\
Total & 80 \\
\hline
\end{tabular}

Table 2. Stage of disease.
\begin{tabular}{|ccc|}
\hline Stage of disease & Number of patients \\
\hline I & 3 & $\mathbf{( 3 )}$ \\
IIa & 11 & \\
IIb & 15 & $\mathbf{( 2 6 )}$ \\
IIIla & 7 & \\
IIIb & 9 & \\
IIIc & 35 & $\mathbf{( 5 1 )}$ \\
Total & 80 & $\mathbf{( 8 0 )}$ \\
\hline
\end{tabular}


Table 3. Intra-operative blood loss (grams).

\begin{tabular}{cc}
\hline Blood loss (grams) & Number of women (percent) \\
\hline $0-99$ & $4(5)$ \\
$100-199$ & $29(36.3)$ \\
$200-299$ & $17(21.3)$ \\
$300-399$ & $13(16.3)$ \\
$400-499$ & $6(7.5)$ \\
$500-599$ & $3(3.8)$ \\
$600-699$ & $2(2.5)$ \\
$700-799$ & $2(2.5)$ \\
$800-899$ & $1(1.3)$ \\
$900-999$ & $1(1.3)$ \\
$1000-1099$ & $1(1.3)$ \\
$1100-1199$ & $1(1.3)$ \\
Total & $80(100.4)$ \\
\hline
\end{tabular}

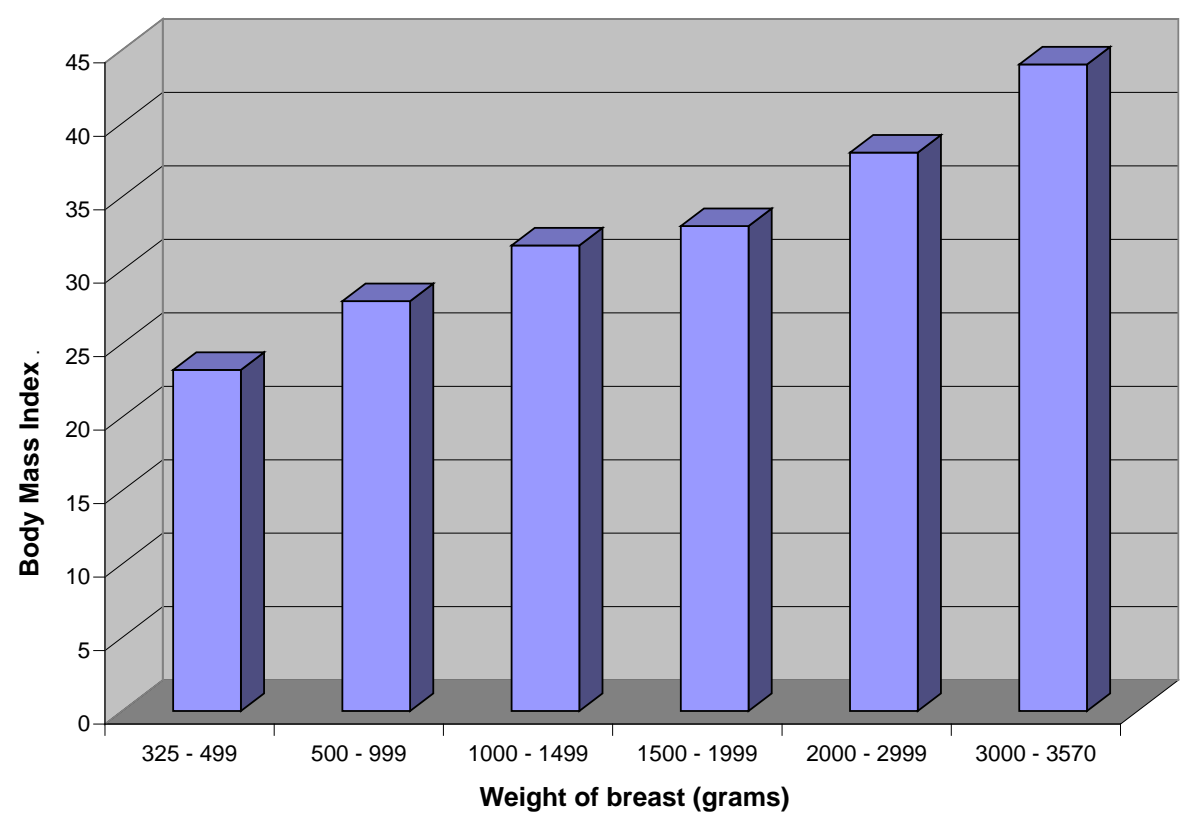

Figure 1. Relating weight of breast of patients to Body Mass Index.

lumes. There was however no positive correlation between breast size and blood loss as indicated by the Spearman statistic $R=0.14286$ with a two tailed $p$ value of 0.75995 .

The blood lost by patients with various stages of disease is shown in Table 4. There was no statistically significant difference in the mean breast weight and mean blood loss for the different stages of the disease; $\mathrm{F}=2.5$, $p$ value $=0.9$ and $\mathrm{F}=1.9, p$ value 0.16 respectively.

\section{Discussion}

Most patients (78.9\%) in this study lost less than $400 \mathrm{~g}$ of blood during mastectomy. The amount of blood lost was higher in extremely large breast weighing more than $2 \mathrm{~kg}$ in which a litre or more blood was lost during total mastectomy and axillary clearance. There was no statistically significant difference between the mean breast 
Table 4. Blood loss by breast weight and disease stage.

\begin{tabular}{cccccccc}
\hline Stage & No & Breast Wt $($ Mean \pm SD) & ANOVA $(\mathrm{F})$ & $p$ Value & Blood Loss (Mean \pm SD) & ANOVA (F) & $p$ Value \\
\hline 1 & 3 & $968.5 \pm 254.6$ & 2.5 & 0.09 & $228 \pm 81.3$ & 1.9 & 0.16 \\
2 & 26 & $862.3 \pm 467.4$ & & & $284.4 \pm 163.8$ & & \\
3 & 51 & $1197 \pm 703.6$ & & & $393.2 \pm 299.2$ & & \\
\hline
\end{tabular}

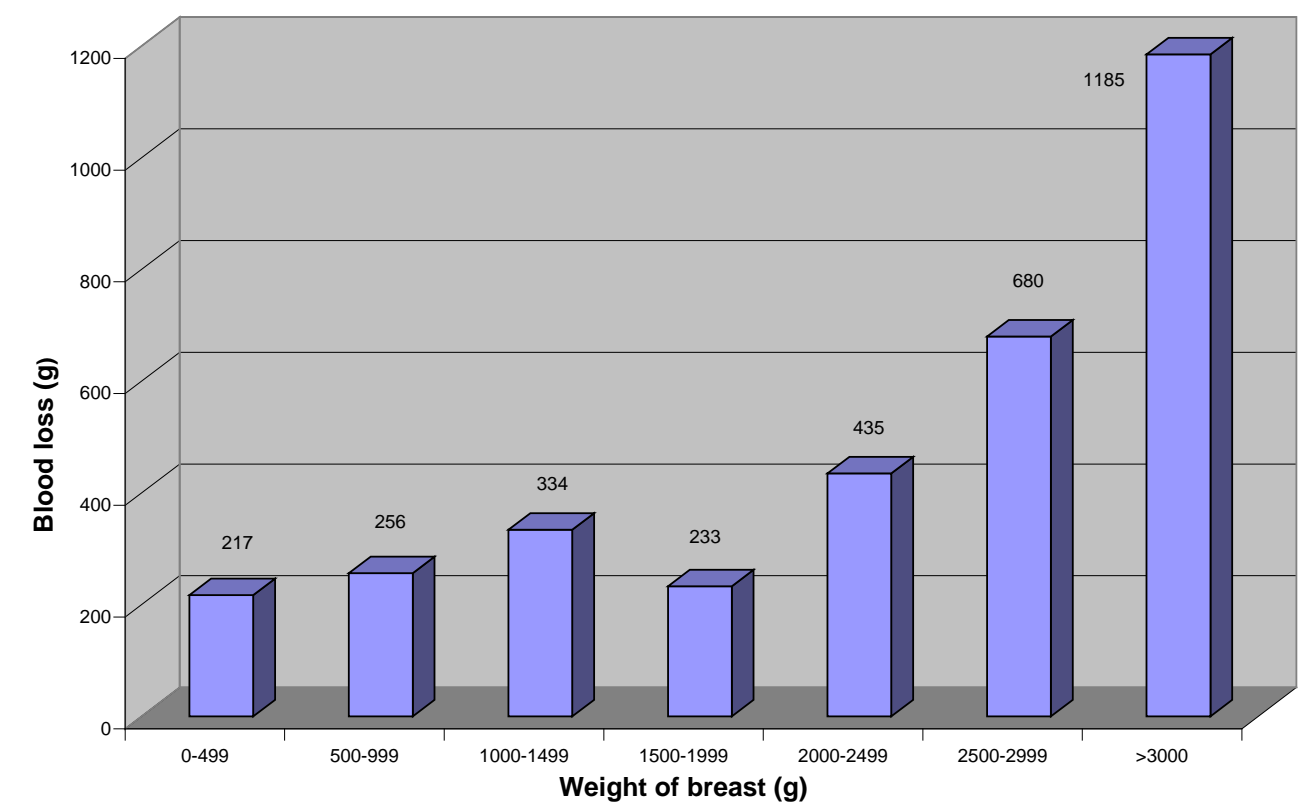

Figure 2. Breast weight and associated blood loss.

weight and mean blood loss for the difference stages of cancer. This is accounted for by the fewer number of patients (2) with extremely large breast weighing $2 \mathrm{~kg}$ in this study.

Total mastectomy with axillary clearance, rather than breast conservation, is the main surgical treatment offered to women presenting with breast cancer in Accra, Ghana. This is because most patients present with advanced disease [8]. In this study of patients having total mastectomy and axillary clearance at the KBTH, 51 (63.8\%) of them had stage 3 disease and 42 (58\%) needed neoadjuvant chemotherapy.

Blood loss during mastectomy depends on many factors. Some surgeons cause more bleeding than others. The surgical technique and available equipment for controlling haemorrhage and minimising blood loss will also influence the amount of blood lost. To minimise these variables, this study was carried out by two surgeons in the same unit who used identical technique and equipment.

The hypothesis being tested was "the blood loss during mastectomy is related to the stage of the disease and the size of the breast".

Blood loss was measured by weighing swabs before and after use. The specific gravity of whole blood is about 1.0621 [10]. The weight of whole blood measured in grams can therefore be approximated to volume in millilitres $\left(\mathrm{cm}^{3}\right)$ of blood. In this study, however, we have maintained reporting the blood loss in grams rather than in millilitres.

Breast size can be difficult to estimate. Although brassiere size is one good way of determining size, it is known that many women do not know their correct brassiere sizes. It has, in fact, been reported that between 80 to $95 \%$ of women wear the wrong size [11]. We therefore weighed the post-mastectomy breast as a measure of size, well aware that such measurements may be difficult to translate to women before mastectomy.

With regard to the relationship between stage of disease and blood loss, we could not draw any conclusions. There was no statistical difference in the mean blood loss for the three stage of disease studied (Table 4). It was noted that all the patients with large breasts ( $>2 \mathrm{~kg})$ in this study had stage 3 disease. Patients with large breasts bled more than smaller breasts, irrespective of stage of disease, thereby rendering the determination of the inde- 
pendent effect of tumour stage on bleeding inconclusive in this study population.

The main conclusions we can make from this study are that most patients lose less than $400 \mathrm{~g}$ of blood during mastectomy, and the amount of blood lost could be considerable in patients with large breasts (more than $2 \mathrm{~kg}$ weight) as they are at risk of significant blood loss (1000 mg or more) during mastectomy. A larger study population will be needed to confirm these findings and also to determine the effect of tumour stage on bleeding.

The significance of these findings is that patients with small breasts are most unlikely to need blood transfusion during and after mastectomy. Those with large breast (estimated to be $>2 \mathrm{~kg}$ ) should have blood crossmatched and care taken to minimise blood loss during surgery. When possible such patients could even be prepared for autologous blood transfusion.

There are limitations to this study. Although the two surgeons who carried out the operations used identical methods, there remains a potential for differences in technique that could affect the amount of blood loss between the two surgeons. Because of the number of variables involved in this study, a much larger sample is needed to draw definite conclusions, especially with regard to the effect of tumour stage on bleeding during mastectomy. Lastly the determination of breast size used in this study (weight of breast) cannot be translated directly when considering a patient for mastectomy.

\section{Conflict of Interest}

The authors have no conflict of interest to declare.

\section{References}

[1] Moersch, R.N., Patrick, R.T. and Clagett, O.T. (1960) The Use of Hypotensive Anesthesia in Radical Mastectomy. Annals of Surgery, 911-918.

[2] Hellevuo, C., Salmi, A., Muuronen, E. and Autio, V. (2002) The Use of Lidocaine with Adrenaline Reduces Blood Loss and Operating Time in Free TRAM Breast Reconstruction. The European Journal of Plastic Surgery, 25, $243-246$. http://dx.doi.org/10.1007/s00238-002-0363-y

[3] Kakos, G.S. and James, A.G. (1970) The Use of Cautery in "Bloodless” Radical Mastectomy. Cancer, 26, 666-668. http://dx.doi.org/10.1002/1097-0142(197009)26:3<666::AID-CNCR2820260327>3.0.CO;2-F

[4] Kurtz, S.B. and Frost, D.B. (1995) A Comparison of Two Surgical Techniques for Performing Mastectomy. European Journal of Surgical Oncology, 21, 143-145. http://dx.doi.org/10.1016/S0748-7983(95)90171-X

[5] Putyrskii, L.A. (1992) The Use of $\mathrm{CO}_{2}$-Laser and Blood Loss during Mastectomy. Ross Med Zh., 5, 16-17.

[6] Deo, S.V.S., Shukla, N.K., Asthana, S., Niranjan, B. and Srinivas, G. (2002) A Comparative Study of Modified Radical Mastectomy Using Harmonic Scalpel and Electrocautery. Singapore Medical Journal, 43, 226-228.

[7] Adwani, A. and Ebbs, S.R. (2006) Ultracision Reduces Acute Blood Loss but Not Seroma Formation after Mastectomy and Axillary Dissection: A Pilot Study. International Journal of Clinical Practice, 60, 562-564. http://dx.doi.org/10.1111/j.1742-1241.2006.00689.x

[8] Clegg-Lamptey, J. and Hodasi, W.M. (2007) A Study of Breast Cancer in Korle Bu Teaching Hospital: Assessing the Impact of Health Education. Ghana Medical Journal, 41, 72-77.

[9] Vibhute, M., Kamath, S.K. and Shetty, A. (2000) Blood Utilisation in Elective General Surgery Cases: Requirements, Ordering and Transfusion Practices. Journal of Postgraduate Medicine, 46, 13-17.

[10] Trudnowski, R.J. and Rico, R.C. (1974) Specific Gravity of Blood and Plasma at 4 and 37 Degrees C. Clinical Chemistry, 20, 615-616.

[11] Wood, K., Cameron, M. and Fitzgerald, K. (2008) Breast Size, Bra Fit and Thoracic Pain in Young Women: A Correlational Study. Chiropractic \& Osteopathy, 16, 1. http://dx.doi.org/10.1186/1746-1340-16-1

\section{Abbreviations}

CAF = Cyclophosphamide, Adriamycin, 5-Fluorouracil;

AC = Adriamycin, Cyclophosphamide;

$\mathrm{CMF}=$ Cyclophosphamide, Methotrexate, 5-Fluorouracil. 
Scientific Research Publishing (SCIRP) is one of the largest Open Access journal publishers. It is currently publishing more than 200 open access, online, peer-reviewed journals covering a wide range of academic disciplines. SCIRP serves the worldwide academic communities and contributes to the progress and application of science with its publication.

Other selected journals from SCIRP are listed as below. Submit your manuscript to us via either submit@scirp.org or Online Submission Portal.
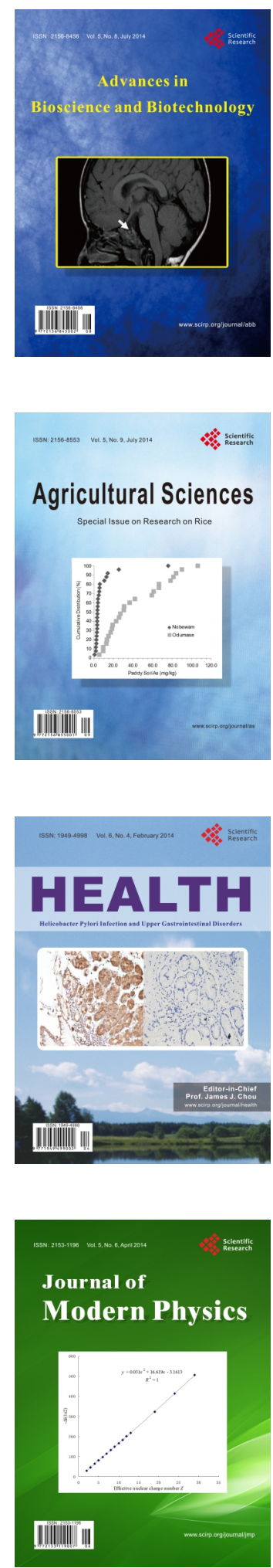
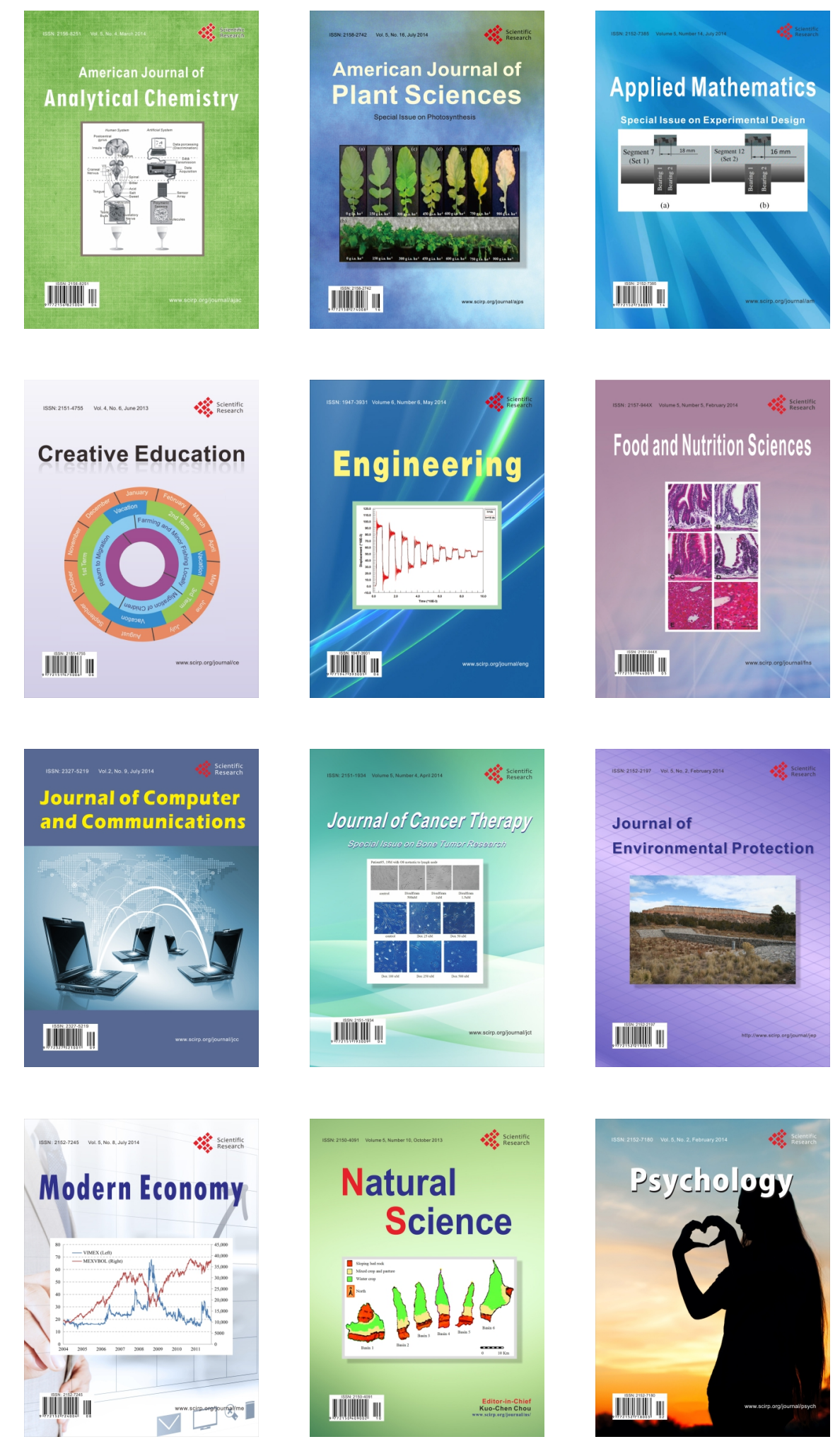